\section{Briginal $\mathbf{s}$ rticles.}

\section{MODERN DIETETIC PRINCIPLES: THEIR PRACTICAI APPLICATION.}

BY W. GILMAN THOMPSON, M.D., Professor of Medicine in the Cornell University Medical College in
New York City.

DURING the past decade there has been very noticeable stimulation of the study of dietetics. The older writers were content to dismiss this subject in connection with many important and common diseases with such meaningless phrases as "the diet should be nutritious," in anemias ; or "it should be bland and more stimulating," in gastric catarrh, and the like, but of late what Von Noorden calls "the new science of nutrition" is everywhere commanding attention. New and valuable books upon the problems of nutrition have appeared, medical journals abound in discussions of the dietetic details of diseases, experimental physiologists and biochemists are furnishing elaborate dietetic studies, and the Department of Agriculture, in co-operation with the various state agricultural experiment stations, has furnished a long series of most instructive investigations of our varied population in our varied climates. Exhaustive calorimeter researches have been made, and new and definite standards have been established concerning the energy-producing value of all classes of foods, and the normal food requirements of the body under opposite conditions of labor and rest, etc. As a nation we have, after many years of effort on the part of a few enthusiasts, finally been made to realize the value of pure food and the crime of food sophistication and have adopted certain legal restrictions which, although primitive, constitute an important right beginning.

The increasing tendency to rely more and more upon hygienic measures and less exclusively upon pills and potions in the treatment of such diseases, notably, as tuberculosis, has done much to focus attention upon the science of dietetics. There are still many opposing theories, due, in part, to fetishism and ignorance of elementary as well as alimentary principles; in part to inherited errors of observation; and in part to the inherent difficulties of formulating specific rules for application under so many necessarily varying conditions as may arise in the progress of any protracted disease; nevertheless, it is safe to assert that more definite progress has been made in the application of dietetics for the sick during the few years of this century than in the many of the preceding one.

It is my purpose briefly to review the present trend of dietetic treatment of certain of the more important diseases which are distinctly influenced by right feeding. The dietetic treatment of typhoid fever has been characterized by gradual and cautious increase in the food allowance ever since Graves, in 1835, began to rescue fever patients from the previous almost absolute starvation practice. Austin Flint, in the early seventies, insisted upon a moderate milk diet of about two quarts (yielding 1,400 calories), and during the past fifteen years many clinicians, notably Frederick S. Shattuck, Fitz, Kinnicutt, Peabody and Manges, in this country, Sir James Barre, in Liverpool, and several other foreign authors have increased the ration during the fever by addition of such foods as eggs, custards, cocoa, bread, purées and scraped beef. Although many clinicians still prefer an exclusive milk, or milk and broth diet during the height of the fever, the tendency is decidedly towards early feeding with semi-solid and solid foods as soon as the temperature begins to abate, without waiting for it to become normal. With increasing experience my custom has been to follow the latter method, and I have never gone to the extreme of some clinicians in eliminating milk entirely throughout the disease, and only temporarily abandon it when diarrhea, tympanitis or hemorrhage make its use unadvisable.

The limit of suralimentation has been attained recently by the exceedingly interesting and exhaustive experiments made by Warren Coleman in collaboration with P. A. Shaffer of the Cornell University Medical College and the results were published in the Journal of the American Medical Association, Oct. 2, 1909. Many of these experiments were conducted in my wards in Bellevue Hospital, so that I had opportunity of observing the cases, and I have employed the method to some extent in the Presbyterian Hospital. It is generally accepted that the loss of weight commonly observed in typhoid fever, and which may amount to 30 or $40 \mathrm{lb}$., is caused by the increased metabolism of the pyrexia plus the destruction of tissue due to specific bacterial toxins. Coleman and Shaffer found that this loss of body weight may be successfully checked in many cases by a diet of carbohydrates of high caloric value. Their experiments were based upon careful daily weighing of the patients, computation of the caloric value of all food digested and estimation of the nitrogen output in the urine and feces.

The minimum energy requirement of a normal man of $150 \mathrm{lb}$. weight, while at rest, is 33 calories per kilo of body weight per diem. It has been demonstrated by Krehl ${ }^{1}$ that in typhoid fever 41 calories are required, upon an average, to maintain nitrogenous equilibrium and counteract tissue waste. In round numbers, this minimum requirement, therefore, amounts to 3,000 calories per diem for a man of average size. Two quarts of milk furnish only half of this requirement, and the usual so-called "liberal diet" for typhoid fever, not more than three fourths. Coleman and Shaffer found that in many cases this minimum was too low, and accordingly gave 4,000 to 5,500 calories. In one case they gave 100 calories per kilo, or 6,000 per diem, the patient's weight being two and one-half times the minimum requirement. Forty-six cases are reported with only one death, that of an ambulatory case of great feebleness when first seen. The effect of the treatment was very striking; the duration of the fever was not lessened, but the percentage of melapses was low and the patients both looked and felt much better 
than is usual with a subnormal diet. The common grave symptoms of the so-called "typhoid condition" were notably absent. In several instances patients gained in weight before the fever abated. In order to supply the high caloric value, milk, sugar and cream were given in large quantity. The total diet for an average of 4,000 calories consists of milk, $1 \frac{1}{2}$ quarts; cream, 1 to 2 pints; $\frac{1}{2}$ to $1 \frac{2}{3} \mathrm{lb}$. of milk sugar; 3 to 6 eggs; butter and a little stale bread or toast. The milk sugar may be given in milk, coffee or cocoa, lemonade, ice cream or custards. It furnishes 120 calories per oz. and is usually well tolerated if allowed in gradually increasing dosage.

My personal experience with this diet has proved fairly satisfactory in some twenty cases in which I employed it last autumn. One patient gained a pound in weight during the fever and several of the others held their weight with very slight loss and without any outward result from the excess of calories supplied.

The milk sugar sometimes causes tympanites, although it is much less likely to do so than cane sugar. When this most undesirable symptom occurs, it is, of course, necessary promptly to reduce the diet to a minimum and exclude sugar, but usually the increased feeding may be resumed again after a brief interval. For some years past I have been in the habit of modifying the diet of typhoid fever patients whose loss of weight was excessive - from one-half to one pound a day - by adding carbohydrate food to the farinaceous gruels and cream. There is a well-recognized adynamic type of this fever in which the thermometric record may be low, but prostration and emaciation are extreme. In such cases, particularly, the increase in the carbohydrate tissue sparers is indicated, and the milk sugar and cream ration of Coleman and Shaffer, in so far as $I$ have observed its effects, is beneficial.

I would formulate my experience by stating the view that the typhoid fever patient should receive sufficient food to spare his tissue waste as completely as possible; that this is better accomplished with carbohydrates than proteids, but that excess which gives rise to any symptoms of indigestion must be checked promptly. The dietetic treatment of gastric ulcer has undergone recent change in the hands of some clinicians, notably Lenhartz, of the Eppendorfer Hospital in Hamburg, who advocates the replacement of the longpracticed starvation system with rectal alimentation by a diet designed to improve nutrition and thereby promote healing of the ulcer, even in cases of recent hematemesis. The diet recommended consists of fresh iced milk (200 to 300 ccm. in twenty-four hours) and 2 to 4 beaten raw eggs iced, given in alternation in small doses every hour. This quantity is slowly increased, and in five or six days, scraped beef ( $35 \mathrm{gm}$.), boiled rice, softened zwieback and cane sugar are added. It is claimed that this diet prevents dilatation of the stomach and the injurious effect of excessive hydrochloric acid secretion upon the ulcerated surface.

It is a truism that many ulcers, like those of the leg, for example, heal promptly in direct proportion with improvement in general bodily nutrition, but rest or freedom from irritation of the ulcer surface is also an important factor to be secured. Putting solid or semi-solid food into the stomach directly after hematemesis from a bleeding ulcer certainly does not fulfill the latter condition and one never knows the size of the ulcer or its exact state prior to operation or autopsy. For several years I have fed cases of this class per os earlier than I did formerly, and I have given trial to the so-called Lenhartz method recently in a number of cases with benefit. Nevertheless, as a routine practice it seems much safer to maintain a more conservative policy, and my present rule after serious hematemesis is to withhold all food for forty-eight hours after vomiting of blood or the rectal passage of clots has ceased, and then to resume feeding per os very cautiously with beef juice, egg albumen or peptonized milk in tablespoonful doses for the first few hours. If no further ill results, I place the patient within two or three days upon ordinary convalescent diet. Gastric ulcer cases occur in two classes of patients, from the standpoint of nutrition: First, those who have extensive longstanding ulcers and resulting emaciation. When they have hematemesis it is often dangerous to feed them actively. Second, those who are in fair health with only slight dyspepsia and who have a sudden moderate hemorrhage from a peptic ulcer, sometimes less than an inch in diameter. These patients often are already wellnourished and do not need forced feeding. The lesion will take care of itself if left alone. A conservative method is, therefore, still to be recommended in the feeding of gastric ulcer cases. Ludin, of Basel, ${ }^{2}$ in a study of 100 cases of gastric ulcer treated in part by the Lenhartz method and in part by the older Leube method, found the percentage of cures and the duration of treatment required did not vary materially under the two methods. We hear much in these days of the evils of gastro-intestinal auto-intoxication. The most scientific as well as practical exposition of this subject from the dietetic standpoint with which I am familiar is Christian A. Herter's work, "Common Bacterial Infections of the Digestive Tract." In this he clearly differentiates the gastric cases due to fermentation with production of $\mathrm{Co}_{2}$ and organic acids from the intestinal cases due to putrefactive changes involving the production of hydrogen sulphide, marsh gas, midal, skatol, indican and other substances of the aromatic sulphuric acid series. The fermentative cases produce symptoms largely mechanical, such as gastric distention, eructation of gas, palpitation due to upward pressure of the diaphragm against the heart, etc. To avoid these symptoms, stalches and sugars must be withheld. The putrefactive symptoms are mainly toxic, affecting the nervous system, such as headache, cramps and excessive fatigue, to avoid which meats, eggs and much sulphur-bearing vegetables, as cabbage and Brussels sprouts, should be withheld. In the more serious combined cases, 
benefit may be derived from a temporary milk we diet for a few days, while catharsis, intestinal auto-fermentatives and copious draughts of water are employed to cleanse the alimentary canal. It is my clinical experience that certain of the cereals are much less liable than others to induce fermentation in these cases; for instance, boiled rice and the so-called puffed rice and finely ground white hominy, boiled, all of which may be taken with a little butter in lieu of sugar and cream, are much less likely than oatmeal or patent breakfast foods to maintain malfermentation in the alimentary canal. "Bananose," or banana flour meal, is another most digestible amylaceous food. Sir Henry M. Stanley lived on it in South Africa all through his worst attacks of gastric fever. Most fruits when dried form a sticky mass like the raisin or fig, but the sun-dried banana may be pulverized into a meal, and the starchy granules are fine, soft and easily digested. Many cases of intestinal putrefaction are benefited by taking the diet of milk fermented by lactobacilline as exploited by Metchnikoff, although probably as much benefit is derived from the simplicity of the food itself as from its specific effect upon the intestinal flora. In some cases, however, the diet is found in a few days to produce nausea and vomiting or loathing, and in such instances the lactobaccilline tablets, if genuine and freshly prepared, I have found decidedly preferable. Patients are apt to confuse ordinary buttermilk, from which the fat has been removed by churning, with the whole milk fermented with lactobacilline, which, of course, is an entirely different product.

Much has lately been written of the supposed advantage of a salt-free diet in chronic nephritis, especially chronic uremia, and for lessening dropsies both of renal and hepatic origin. In so far as uremia is concerned, the conflicting evidence at present produced shows that it is often observed when the salts of the tissues and blood are normal or subnormal, and, on the other hand, that when the salts are increased, uremia does not necessarily result. The experimental studies deal largely with ammonium and potassium salts, which are more difficult to exclude from the diet than sodium chloride. In common with the general clinical practice I have been accustomed for many years to treat serious uremic symptoms with hot saline rectal injections and transfusion of saline solutions after phlebotomy, and I have not seen any benefit whatever from the absolutely salt-free diet in such acute cases, where the small quantity of salt withheld from the dietary is necessarily offset by the other therapeutic measures. In general anasarca, either of cardiac or renal origin, in ascites of renal origin, and in serous accumulations in the pleura or pericardium, the problem is different. It is not an urgent question of toxemia, but of the possibility of modifying the density and reaction of the blood so as to determine osmosis in a reverse direction, determine reabsorption of transudates and stimulate renal elimination of water without overtaxing the renal epithelium with salts. Just here we meet with conflicting clinical evidence. On the one hand it is claimed by Widal, ${ }^{3}$ Javal, Joseph I. Miller, ${ }^{4}$ G. L. Peabody and many others that a histo-retention of chlorides precedes the accumulation of water in the tissues and that a salt-free diet promotes absorption of dropsical effusions. On the other hand is the clinical experience that in many cases the method so strongly advocated by Matthew Hay in his monograph on saline cathartics, of giving mixed saline purges in concentrated solution, proves highly efficacious. My personal experience with cardiac and renal dropsy is that the intravenous injection of crystalline strophanthin (in doses of $0.25 \mathrm{mgm}$.) combined with administration per os of a few 5-gr. doses of theosine does more in twenty-four hours to relieve anasarca than days of treatment by the salt-free diet. After persistent trial in a large number of cases I have never met with the striking results attributed by many writers to the salt-free diet, and while it can do no harm, I have found its results often practically $n i l$, and it certainly should not be depended upon to the exclusion of such long-tried therapeutic measures as diaphoresis, restriction of fluid intake, catharsis and diuresis. However, it gives the kidneys a little less elimination to perform and may, therefore, be employed in connection with other measures. Fresh butter, bread without salt, rice, potatoes, fresh fish, all cooked without salt, constitute a sufficently varied menu, which, while not strictly salt-free, is sufficiently so for all practical purposes. Much harm has arisen through the old-fashioned belief that in the chronic nephritic all the albumin ingested as food reappears as such in the urine. I am quite in, accord with Croftan, who says: ${ }^{5}$ "There is no compelling reason why a mixed diet should not be given in these cases." Reasonable variety may be allowed provided those foods whose end products, like the purin bodies, may become irritating or difficult of elimination be not taken in excess. A too prolonged milk diet in these cases has many objections, especially when the patient is able to go about, for in order to obtain sufficient calories to maintain nutrition, too much fluid is ingested, the anemia is liable to increase and biliousness ensues. I am accustomed in such cases to allow fish, eggs and chicken ad libitum, and a restricted red meat ration once or twice a week. It is a common fallacy to suppose that chicken differs essentially in composition from beef, but patients are not so apt to eat it too heartily. To vary the monotony of chicken, the well-to-do may eat occasionally the more expensive capon, turkey, guinea fowl or squab. There is decided tendency at present to avoid the excessive ingestion of water in chronic nephritics. It is often the custom to encourage the chronic nephritic to drink large quantities of fuid, either as plain water, vichy or carbonated water, etc., in addition to the large percentage of water in: a milk diet, with the twofold object of washing. out the casts which plug the tribules and diluting the toxins which may accumulate in the blood. On the other hand, the chronic nephritic is very. 
sensitive to increase in blood pressure, his arteries being thickened and unyielding. To overload their system with large quantities of fluid, quickly absorbed from an empty stomach, may result in overtaxing both heart and kidneys. Moreover, many chronic nephritics possess some serious heart lesion, and to strain the heart by increasing its work results in enfeeblement of the circulation and congestion of the chronically diseased kidneys. Nephritic disease of long standing is accompanied by anemia and a tendency to dropsy, both of which conditions may be made worse by diluting the blood. It is difficult to formulate general rules, for, in a given case, conditions change from time to time and a subnormal allowance of fluid may prove as harmful as an excess. I have lately seen an interesting illustration of the overwork of a diseased kidney. A young pregnant colored woman presented herself with all the evidence of a right-sided pyonephrosis with a tumor, pain, septic temperature, leucocytosis and colon bacilli in the urine. In order to determine the character of the urine more definitely, both ureters were simultaneously catheterized for me by Dr. Osgood at the Presbyterian Hospital, and it was interesting to find that the rate of secretion from the diseased kidney was exactly four times that of the normal one. To force such a patient to drink eighty more ounces of fluid daily would doubtless result in still further overtaxing a kidney in which there were evidences of nephritis as well as of purulent inflammation of its pelvis.

My custom in regard to fluid ingestion in chronic nephritis is to modify the quantity carefully in each case, seldom diminishing it below a normal standard of $50 \mathrm{oz}$. per diem, except temporarily to promote reabsorption of dropsical fluids, and increasing it moderately by 20 or $30 \mathrm{oz}$. when casts accumulate and the quantity of urine is dangerously small, when sweating is artifically induced or when large quantities of fluid have been drained off by hydragogue catharsis. The occurrence of general anasarca, extreme anemia and cardiac dilatation or pulmonary edema are all conditions demanding a restriction rather than an increase of ingested fluids. In such cases I sometimes temporarily withhold milk from the diet, in whole or in part, and substitute semisolid food in order to avoid giving too much fluid.

The oatmeal diet for advanced diabetes was elaborated by Von Noorden a half dozen years ago upon the theory that the proteid of this cereal was sufficient to satisfy the needs of the body without the danger of acidosis from excessive meat consumption and that the system could acquire toleration for the starch which it contains. The oatmeal is prepared with butter, water and egg albumen and given in a quantity to supply the necessary 3,000 calories of energy. I am not aware that the Scotch, who consume large quantities of oatmeal, are especially immune from diabetes, and my experience is that patients in this country will not long tolerate so monotonous an equine diet. The problem has been much discussed in the literature of late, and the system has been equally endorsed by some authors and condemned by others. Thus, Lipetz, ${ }^{6}$ for example, found that oatmeal greatly augmented the intestinal flora, indicating more active fermentation, and in one of his patients the diet increased both the glycosuria and acidosis. Such varied points of view can only be explained through the failure to discriminate between the different types of diabetes. The oatmeal diet should be regarded in no sense as a "cure" for diabetes in general. As Alfred C. Croftan " says, "It is worse than useless in mild cases occurring in adults or in senile individuals" in whom the glucose disappears from the urine shortly after withdrawal of carbohydrates, and in others in whom more gradual lessening of the glucose and elimination of acetone is accompanied by restitution of the general health. He adds that he has seen such cases on oatmeal feeding converted into severe and permanent types of diabetes. In his experience the treatment gives best results in mild juvenile or adolescent types, and in a few severe cases among adults as a last resort, and in such cases if proteid diet is resumed it should be given very gradually and with much watchfulness. In no case should the diet be enforced without daily examination of the urine and comparisons of the body weight and other symptoms.

In my own cases I have preferred to employ oatmeal not as an exclusive diet for adult diabetics, but as a form of amylaceous food to compose the chief daily allowance of such material in lieu of breadstuffs. Oatmeal is a "satisfying" food and lessens to a great extent, when used within the limits of a half dozen tablespoonfuls daily, the craving for starchy foods and sweets which in the starving diabetic often becomes a definite and exaggerated symptom. This craving is not relieved by any form of gluten bread, gluten meal or bran, and I have not prescribed gluten for many years. Such preparations are notoriously unreliable, most of them contain a large percentage of either sugar or starch, they are expensive and many patients who are allowed to use them fall into the error of thinking they may eat unlimited quantities. It is far better to allow a definite measured portion of oatmeal, toasted bread - two or three slices three inches square and half an inch thick - or one or two small baked potatoes, which latter contain, bulk for bulk, about half as much starch as wheaten bread. Another debatable question in the dietary of the diabetic is the danger of producing acidosis and possibly coma by an excess of fats and meats. Whether or not such a diet is directly causative of these symptoms, it is generally conceded that when they supervene it is desirable to substitute a considerable percentage of carbohydrate food, at least temporarily. A factor often neglected in the treatment of diabetes is the psychic influence of depression, and there are many cases in which clinically, and apart from the urinalysis, benefit is derivable by a temporary freedom in diet. Few diseases better illustrate the value of occasional radical change in any menu. I often recall the case of an elderly man with serious diabetes to 
whom I gave a very strict proteid dietary. $\mathrm{He}$ continued faithfully to follow the régime as he did to lose in weight and strength, until he came one day to my office and literally, with tears streaming down his face, begged for the buckwheat cakes and maple syrup to which he had been accustomed for fifty ycars. I allowed him to take the risk; he promptly gained $15 \mathrm{lb}$. in weight, the sugar fell from 5 to $1 \%$ and with subsequent alternate restrictions he lived comfortably for a half a dozen years, dying finally of apoplexy, not diabetes. 'The best rule for diabetes is that of elasticity and the recognition of the varied types and individual peculiarities of the disease. 'The problem is summarized by Eugene Dubois and B. S. Veeder ${ }^{8}$ as a result of elaborate calorimeter experiments upon two diabetics. "The total energy requirement of cases of diabetes does not vary from the normal. In addition to the 31 to 35 calories (per kilo of body weight) required for the normal individual at rest, the diabetic should bo given enough extra calories to cover the loss of sugar in the urine. If this is not done there is a breakdown of the body protein and fat." Von Noorden cites twelve other cases similarly studied, with practically the same conclusion.

The dietetic principles in feeding the tuberculous have undergone some degree of recent modification in that forced feeding or suralimentation is less insisted upon. Prof. Irving Fisher, himself an apostle of reduced diet, gathered data from ninety-five leading sanatoria for the tuberculous in various countries and found that in a decided majority excessive feeding had been given up, although some still allow 5,500 calories. Every one knows that the thin tuberculous patient is doing well as long as he gains in body weight up to the normal or maintains a high standard of healthful nutrition, but in the process he may be sometimes overfed. I still believe it to be a good rule to give a tuberculous patient in the early stages all the nourishing food - meats, eggs, fats, such as butter, cream and bacon, cereals and fresh fruit and vegetables - that he can be made to digest without becoming constipated or bilious, overloading the urine with organic waste and the intestines with the putrefactive residue of an excessive meat ration. It is also a good rule periodically, once in about three weeks, temporarily to reduce the quantity of food by omitting luncheons between meals and to give a cathartic in order to prevent overloading the system with accumulated waste products. Debove's method of forced feeding in grave cases with a stomach tube is carrying the matter somewhat too far and is seldom to be recommended except sometimes in laryngeal tuberculosis when the pain of deglutition inhibits swallowing.

In the treatment of obesity there have been more so-called diet "systems" and "cures " than for any other ailment. One difficulty is that dietetic treatment is seldom seriously followed by the patient until it is too late, when the patient claims that he is a very light eater, and so he is, usually at, say, 250 or $300 \mathrm{lb}$. Such a man in my wards at present is actually gaining weight on a diet of
900 calories, or less than one third the normal, and I cannot stop him. In a given case so much depends on the patient's ability to exercise, the absence of complicating circulatory or other disease, the patient's self-control and many other factors that it is impossible within the limits of the present review to enter further into this discussion. The published researches of Ton Noorden on obesity ${ }^{\circ}$ present the best modern guide for treatment of this disorder of metabolism. I am often asked by the parents of children who have had acute articular rheumatism what diet will prove prophylactic. If this be an acute infection, as it is now generally believed to be, there is probably little hope of its dietetic prevention, although the dietetic treatment of the acute attacks is well understood. In the intervals, if the growing child be too long deprived of proteid food, he is apt to remain anemic and possibly be retarded in development. My rule in such cases, in addition to excluding everything liable to produce dyspepsia, is to order a periodical dietetic training, so to speak, once in three or four months. That is, for periods of three weeks to exclude meat and most saccharine foods, to urge the drinking of large quantities of water, give an alkali and occasional catharsis. This system may not always prove successful, but often seems to be so, and I know of nothing better to do. A very interesting field of modern dietetics is found in the determination of the variety of urinary nitrogen excreted, that is, of the relative percentage of the urea nitrogen, the ammonia nitrogen, the creatinin nitrogen and uric acid nitrogen, in comparison with the quantity and quality of proteid food ingested in various disorders of metabolism such as obesity, gout, diabetes, etc. The careful analysis of this type made by James Ewing and C. A. L. Wolf, of the Cornell University Medical School, ${ }^{10}$ shows that valuable conclusions may be drawn from this research in acute yellow atrophy, eclampsia and other toxemias of pregnancy, but the work requires much time and labor and the habit, still prevalent, of drawing conclusions from a single quantitative urea test, especially without definite statement of the quantity of proteid food previously ingested is worse than useless. 'There is much work to be done in this comparatively new field by those who can command the skill and material to undertake it before such tests can be made feasible and reliable for clinical deductions by the general practitioner. In any given case it requires several days to establish nitrogen equilibrium in a patient upon a fixed diet, and meanwhile, if the case be acute and serious, many complicating factors must be taken into consideration. The more chronic disorders involving metabolism, such as obesity, diabetes, pernicious anemia, carcinoma, etc., offer the most promising field for such investigations. To make them complete, however, in relation to food intake, the latter should be checked by analysis of the fecal output, which, of course, adds materially to the labor of the research.

The purin-free diet is merely a new name for an old system. It comprises the exclusion of the purin bodies, namely, uric acid, hypoxanthin, 
xanthin, adenin and guanin, and consists essentially in the exclusion of meats, sweetbread, liver, kidneys, fish, legumes and certain other vegetables, such as asparagus, together with tea and coffee, alcohol, and the substitution of milk, cheese, eggs, nuts, cereals, such as breadstuffs, hominy and rice, potatoes, fats, sugars, fruits and nuts. It is practically the diet of many Polynesian savages who have no meat on their islands. It is particularly recommended in such eonditions as gout, lithemia, arteriosclerosis, rheumatism, migraine and certain other neurotic conditions. It is undoubtedly a useful diet in many of these disorders provided it be not too suddenly adopted by those of diametrically opposite habits, or too long continued, and care should be taken that the patient does not become anemic or constipated. On the other hand, it is not a diet suitable to build up physique in the young of our race or to increase resisting power against disease. I knew an elderly man who discovered it for himself and lived on it comfortably for a dozen years until he was past eighty, but he had the unenviable physique of an animal after long hibernation. I have found this diet most useful in a certain class of neurasthenics who have been heavy meat eater's and who have long replaced the factors of exercise and fresh air by sedentary habits and worry or accumulating responsibilities. Such patients suffer much from muscular fatigue, often of painful degree, headaches and neuralgias, insomnia and psychic depression. My custom is to proscribe all meats, alcohol, tea and coffee from the dietary for at least three weeks, and then in ordinary cases to permit the eating of meat sparingly once or twice a week for a month, and thereafter to restrict its use to very small quantities, eaten never more than once a day. I have not found it necessary or desirable to go so far as to exclude the purin-bearing vegetable foods, for they are seldom eaten to excess and are not primarily at fault. There is at present a gratifying change of view as to the dietetic necessity of alcohol in the treatment of disease. We no longer regard beer as a necessary support to the nursing mother, malt liquors as a mainstay in phthisis, or Burgundy as a sheet anchor in anemia. As a hospital interne, now more than twenty-five years ago, I was brought up to regard alcohol as a food. I was taught to give whiskey in typhoid fever and pneumonia to the extent sometimes of an ounce an hour and all day long, and to feed babies with diarrhea or diphtheria on brandy. At present I never use alcohol in pneumonia except in a few cases among the very aged or cases complicated by delirium tremens. Not infrequently I order no alcoholic beverages for weeks at a time in my general medical wards, preferring as cardiac supports the true cardiac drugs and the diffusible stimulants such as ammonia, camphor, etc.; occasionally, in adynamic typhoid, a few doses of whiskey, and in tiding over an emergency, and it is useful in occasional crises of other sorts, to be discontinued as soon as the danger has passed. There are cases, especially among the aged or debilitated, in which the malt liquors or sometimes the stronger liquors, diluted, seem to aid digestion or aid in overcoming insomnia, but in general I find myself in full accord with the modern tendency to prescribe less alcohol every year. In the hospitals of Paris and of Italy one finds a bottle of vin ordinaire standing by the bedside of every patient, as one sees beer given in routine to hospital patients in Germany, but in this country I do not find that patients of these foreign nationalities (and I see many of them in Bellevue Hospital) either need or demand the routine use of alcohol when ill. Richard Cabot ${ }^{11}$ has shown by a graphic: chart that in the Massachusetts General Hospital the average per capita cost of alcoholic stimulants fell from 57 cents in 1899 to 13 cents in 1907. There was also a concident fall in the cost of medicines per patient from $\$ 1.92$ to $\$ 0.92$, all which took place by a uniform yearly decline. I have been unable to obtain exact data from the hospitals with which I am connected, owing to shortcomings in bookkeeping methods, but I am confident that a similar decrease has occurred in very many medical institutions. 'The present per capita consumption of alcoholic beverages in Bellevue Hospital, with an average of 1,000 patients, shows a cost of eight to ten cents a month, but a large special alcoholism service of over 6,000 patients per annum makes the average cost much higher than it otherwise would be. Last month the average per capita consumption of alcohol per patient for the month was less than one dram, which, of course, means that a very large proportion received no alcoholic beverage at all. Sir Victor Horsley showed, in 1906, that in the London hospitals during the preceding forty year's the consumption of milk and alcohol had been exactly reversed, that of alcohol being reduced to one third. It is an interesting fact that just as no one food produces any specific disease, unless it be contaminated by fungoid or parasitic growths, as in the case of pellagra or trichinosis, so also no one food is specifically curative of any disease, with the single exception of the cure of infantile scurvy with orange juice, which affords the most striking illustration of dietetic response. Scurvy, which used to decimate the armies and especially the navies of the world in former years, is now no longer dreaded, and the promptness with which a few spoonfuls of fiesh orange juice will banish the most serious symptoms of scurvy in infancy is a most gratifying dietetic triumph. Akin to scurvy as a disease of dietetic deprivation is beri-beri, and its practical extermination by Baron Takaki from the Japanese navy by the introduction of barley and meat into the ration to replace the excessive use of white rice represents another brilliant triumph of scientific dietetics. Referring to scurvy in infants suggests the topic of so-called "proprietary foods," for to their prolonged use with the total exclusion of fresh milk from the infant dietary must be attributed deaths from scurvy which were formerly so frequent but which have lately become almost unknown in this country. Speaking generally, proprietary. foods are expensive and unnecessary, if not worse 
than useless. Personally, I rarely prescribe any of the so-called meat extracts or peptonoid preparations, preferring to use fresh and pressed beef juice whenever any food of this simple class is desired. 'The Council on Pharmacy and Chemistry of the American Medical Association has done most admirable work in exposing in the pages of the Journal the humbug of many such proprietary and alleged predigested foods, not a few of which depend largely for their success among the laity upon the considerable percentage of alcohol added as a preservative. I quote the following criticism from an admirable editorial in the Journal of the American Medical Association of Nov. 20, 1909: "Anything that lays claim to being the best part of good red beef sounds so nourishing that the name itsclf makes people feel fed. It is humiliating but most enlightening to pliysicians who have used such preparations to lea'n that these are not beef juice at all. It is even more important to note the surprisingly low calorific value. All the advertising arguments conceivable, all the specious claims that can be advanced, cannot change the fact that to give a patient a microscopic fraction of the amount of energy that he necessarily expends is starvation." An instructive series of analyses of the various proprictary meat juices and extracts given in this Journal ${ }^{12}$ demonstrates the fallacy of regarding such preparations as representing in any notable degree the food values of the meats from which they are derived. Similarly, many of the muchadvertised proprietary or medicinal farinaceous foods present no dietetic advantages which may not be both cheaper and better obtained through proper use of the natural starches of fine hominy, farina, rice or cornmeal. 'There are occasional cases among adults in which from temporary convenience or a personal idiosyncracy in digestion proprietary foods such as the well-known Imperial Granum or malted milk may prove serviceable. Post-operative patients with feeble digestive powers and cases of serious organic gastric disease may demand some degree of the predigestion of both proteids and starches, but this is usually best attained by the fresh digestion of ordinary foods at the time of use. The socalled " concentrated" proprietary foods are for the most part delusive in the actual caloric value that they supply and should give place as soon as possible in a given case to the natural foods.

The concentrated army rations employed for forced marches, while not adapted for any weakness of digestion, illustrate the limit to which food concentration may be successfully carried for temporary use without loss of energy. The elaborate experiments long conducted in the German army, and more recently in our own army, have demonstrated that the most sustaining dry foods for this purpose are: chocolate for sugar, fat and carbohydrate; raisins for sugar; pea meal for proteid and carbohydrate, with some form of fat, such as suet, which will not become rancid. Commenting on the prevailing dietetic theories of this country, an English writer, A. Bruce, published the result of a personal study in the Brilish Medical Journal for Dec. 11-18, 1909. He finds the principal theorists divisible into the "Hesh abstainers," who do not exclude the purins of soup or the xanthins of tea and coffee; (2) the "purin-free diet advocates," who allow much proteid and claim that purin exclusion is all that is necessary to maintain or restore health, and (3) the "low-proteid advocates." He also comments on the frequent absence of other directions as to regulation of exericse and fresh air and the abuse of tobacco and alcohol. He is certainly correct in assuming that there is no field of therapeutics in which such random ill-substantiated theories have hitherto prevailed as in that of dietetics, and in which enthusiasts have often become so blind to co-ordinate factor's of health. Dietetic fads we have always with us, but more so than ever at the present time, doubtless owing to their ready exploitation by the public press. They have often been devised by laymen like Cornaro and Banting, not to mention familiar names of recent date. They concern the manner of eating, the quantity of food and its quality, and present the common error of reasoning from the singular to the many by those whose experience is solely derived from self-centered observation without adequate knowledge of the dictetic habits of the various races of man. 'The chief error lies in claiming that a special group of foods or a special quantity of food is a universal preventive of disease and is of universal adaptability to men living and working under diametrically opposite conditions or environment. 'The Norther'n Eskimo and the primitive North American Indian, subsisting exclusively upon animal food, proteid and fat; the Congo savage, subsisting upon plantains, and the primitive South Sea Islander, subsisting upon fish and fruits, present no marked differences in physique, endurance, longevity or resisting power to disease which are directly traceable to the nature of their food more than to any other environmental conditions. 'They acquire rheumatism, tuberculosis and many other maladies with equal readiness when opportunity presents. 'The Japanese are at present trying to raise their stature by more universal meat eating, but their diet already contains more proteid than is generally supposed, and it will be interesting to see whether the next generation can be modified by a dietetic experiment on a greater scale than has probably been heretofore undertaken. Prof. $\mathrm{R}$. H. Chittenden (my good friend and former laboratory instruotor) has been at great pains to prove ${ }^{13}$ that a selected group of healthy young men, soldiers and students, can maintain nitrogen equilibrium, endure vigorous exercise and remain in good health on less than half the quantity of proteid food ordinarily eaten. Without depreciating the value of his scientific experiments, it is difficult to see wherein they may lead to practical results. Graham Lusk, commenting in his "Science of Nutrition" (1909) on this question, says (p. 219), "Chittenden has fallen into error in the commendation of 2,500 to 2,600 calories as an ample diet for a soldier at drill," and adds that many of his con- 
clusions, being drawn from weight alone, "can only be of the roughest character."

Major Charles E. Woodruff, U. S. A., the foremost student of the diet of the American soldier, has lately traced the after-history of the soldiers experimented upon, who in some instances suffered severely from the experiments and would have done so still more had they not surreptitiously indulged in extra meals.

We are in possession of dietetic experiments conducted not upon a score of men, but upon many thousands, made by the studies of our Department of Agriculture, and by our own and foreign armies, showing what excellent work is done on a full proteid ration. Our troops in the late Spanish war fought better in the tropics when the refrigerator meat vessels reached them, even though the beef was more or less "embalmed." Henry M. Stanley wrote of great feats of endurance by Congo natives on a carbohydrate diet of plantains, and every Arctic explorer up to Commodore Peary has told of similar feats of endurance by the Eskimos on a diet composed principally of proteid. In a somewhat varied hospital experience I have had occasion from time to time to feed Eskimos, Hindoos, Chinese, Turks, Greeks, Arabs and representatives of many other nationalities, and with the exception of the Brahmin, whose diet is controlled by religion, I have found them all quite willing to eat the varied diet that was set before them. In fact, the broad dietetic principles of the human race are directed by the factors of environment, occupation, heredity and individual experience and are not to be prescribed by the isolated experiments of a few robust young subjects conducted for a limited period of time. That most Americans consume more proteid food than they need, in fact more food of every kind than they actually require, is doubtless true, yet nature has provided an ample cloaca maxima, and on the whole our $90,000,000$ mixed population is holding its own fairly well in the world's competition on a liberal mixed diet and with a constantly increasing longevity ratio. Another cardinal principle of sound dietetics is not to continue the dietetic treatment of a local or special condition so long as to impair the general health in other ways, or, as Robert Hutchinson says, "14 " not to sacrifice the whole for a part." For example, too rigid exclusion of meat from the diet may increase the anemia; too narrow a diet limitation in chronic gastritis or ulcer may lead to emaciation and debility and thereby prevent recovery, and in some cases of diabetes the psychic depression produced by total obstention from saccharine and amylaceous food may greatly aggravate all the symptoms.

In conclusion, I would plead for the more accurate caloric estimation of dietaries by the general practitioner. Absolute accuracy can seldom be attained outside of the hospital and laboratory, but sufficiently reliable data for ordinary clinical use may now be secured easily without special technical skill and without irksomeness for the patients. Tables are accessible giving the energy value in calories of all the foods in common house- hold measures, such as tablespoonfuls, and one of the most practical of such tables has been published by Dr. Horace D. Arnold, of Boston. Moreover, Dr. Hart, of New York, has devised a small and most convenient dinner table scales (made by John Chatillon \& Sons, New York) which may be used by the patient. An empty dinner plate is set upon the scales, a movable dial is turned so as to deduct the weight of the plate, and before each article of food is added the dial is again turned to zero to give the exact weight of the food without the trouble of arithmetical calculation. Instead of being boresome, patients find its use entertaining, and diabetic and obese patients especially soon learn to measure accurately the proportions of their various foods.

\section{REFERENCES.}

1 Principles of Clinical Pathology. Hewlett, trans. Phila., 1905. 2 Arch. fúr Verdauungskrankh., Berlin, December, 1909, xv, No. 6. 8 Presse Méd., xli, 1903.

Jour. Am. Med. Asso., Dec. 23, 1905, pp. 1915-1917.

I Ibid., June $24,1905$.

- Zeitschr. fur Klin. Med., vol. lvi, 1900.

7 Jour. Am. Med. Asso." April 24, 1909, p. 1313 et seq.

8 Arch. Int. Med., 1910, vol. v, pp. 37-46.

Disorders of Metabolism and Nutrition, Part I, 1906

10 Am. Jour. Obstet., 1907, vol. Iv, No. 3 .

11 Boston MED. AND Sora. Jour., April 15, 1909.

12 Jan. 23, 1909 , pp. 311, 312 .

13 Physiological Economy in Nutrition, 1904.

\section{SOME CLINICAL ASPECTS OF PULMONARY EMBOLISM.}

BY GEORGE G. SEARS, M.D., BOBTON,

Visiting Physician, Boston City Hospital; Assistant Professor of
Clinical Medicine, Hartard Medical School.

The pathological records of the Boston City Hospital show that pulmonary embolism and infarction are fairly common post-mortem findings, since they were present 106 times in 3,006 autopsies, about $3.5 \%$. How frequently such cases appear in ordinary practice does not admit of statistical expression, but the unusual number recently seen by the writer, after attention had been particularly called to the subject by the occurrence of two or three striking instances, has raised a question as to the frequency with which they are overlooked, because their possibility is not considered in making a differential diagnosis.

Some cases must necessarily escape detection because they cause no symptoms; others because they are terminal events occurring when the patient is already in a serious condition, if not in extremis, and the symptoms are confounded with those of the primary disease; but too many remain undiagnosed because the attention is fixed on certain prominent phenomena or group of phenomena instead of on the whole clinical picture as presented by the history and the physical signs.

Between the cases in which no symptoms are recognizable and those in which life is suddenly ended as the result of syncope or asphyxiation from plugging of a primary branch of the pulmonary artery, symptoms of all degrees of severity and distinctiveness are found. The most important of those which may occur at some time during the progress of a case are a sudden feeling of pain, which may be intense, oppression 